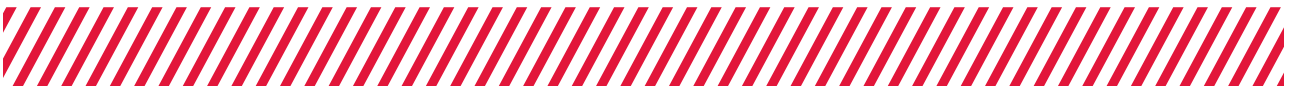

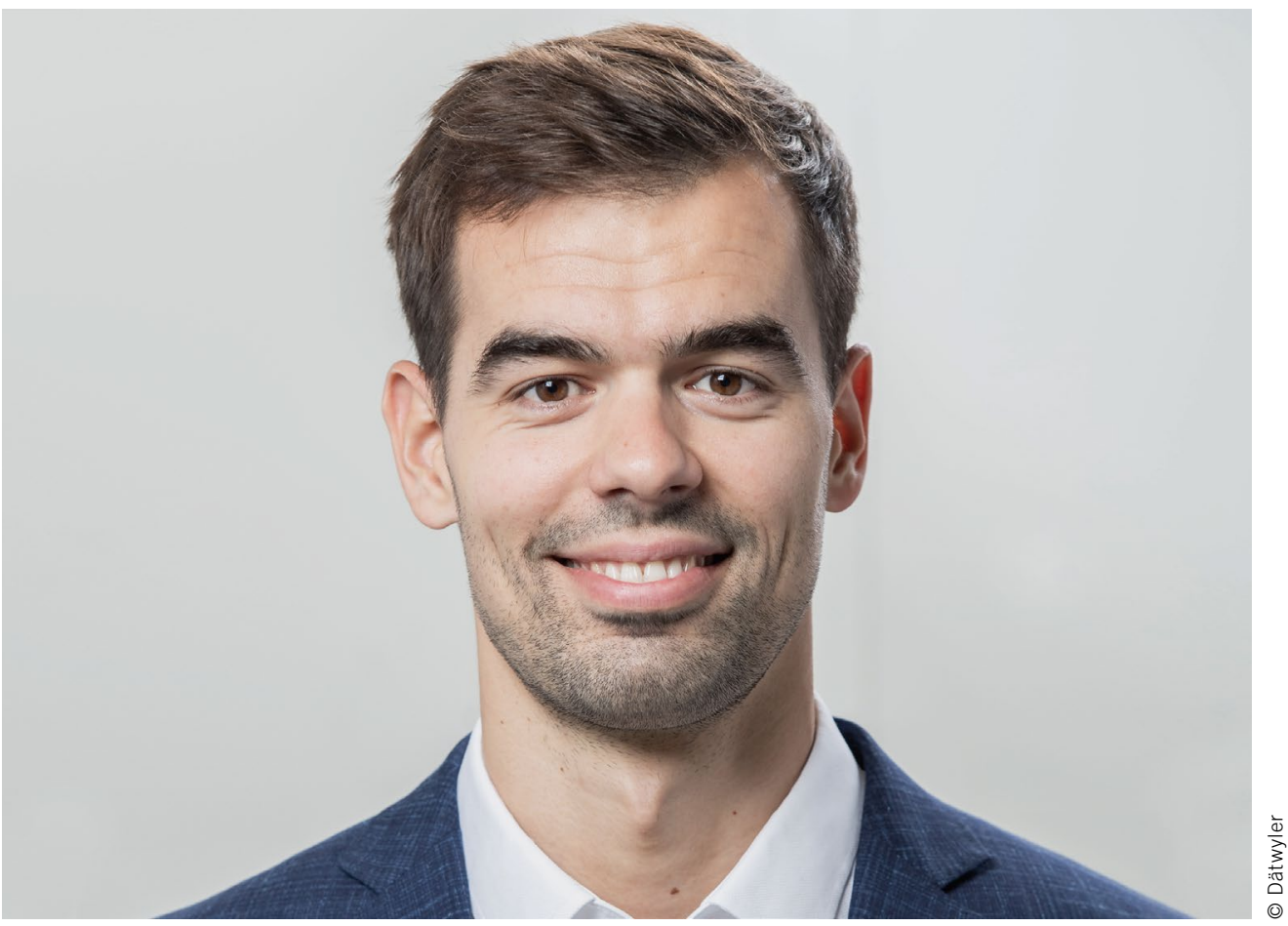

Dr. Jakub Kadlcak

Head of Materials Development and Surface Technologies bei

Dätwyler Mobility

\section{Batterien gut temperieren und abdichten}

Durch die zunehmende Elektrifizierung nehmen auch bis dato sekundäre Bereiche wie das Temperieren von Batterien einen größeren Stellenwert ein. Das Thermomanagement in Elektrofahrzeugen zielt auf allzeitig optimale Betriebsbedingungen dieses Energiespeichers ab und ist daher von deren Temperaturregelung abhängig. Die Betriebstemperatur der Batterie hat einen direkten Einfluss auf deren Leistungsfähigkeit, hält deren Kapazität aufrecht und hat Auswirkungen auf Ladezeit und Allgemeinzustand. Überhitzung und potenzielle thermische Ausreißer können zudem die Sicherheit der Insassen gefährden, weshalb die Temperaturregelung von äußerster Wichtigkeit ist.

Nach unserer Auffassung bei Dätwyler kann das Thermomanagement durch den intelligenten Einsatz geeigneter Werkstoffe und Komponenten deutlich verbessert werden. Ein überzeugender Weg ist es, die Batterie in eine dielektrische Flüssigkeit zu tauchen. Durch diese direkte Flüssigkeitskühlung kann die Batterie erwärmt oder abgekühlt werden, ohne dass Wärmetauscher benötigt werden. Dies trägt zur Effizienz der Batterie bei, reduziert gleichzeitig deren Gewicht und vereinfacht ihre Konstruktion.

Als Abdichtung der dielektrischen Flüssigkeit können elektrisch und thermisch leitfähige und elektromagnetisch abschirmende Materialien genutzt werden, kurz Etemi-Werkstoffe genannt. Das dazugehörige Projekt umfasst eine große Band- breite an Dichtwerkstoffentwicklungen, die von gewöhnlichen Elastomeren über Flüssigsilikonkautschuk bis hin zu Thermoplasten reicht. Damit wird sichergestellt, dass Kunden, die Hybrid- und batterieelektrische Fahrzeuge entwickeln, das volle Potenzial systemkritischer Dichtungselemente mit fortschrittlichen Funktionen ausschöpfen können. Dazu zählen das Versiegeln des Akkupacks mit wärmeleitendem Elastomerwerkstoff zur Gewährleistung struktureller Stabilität, zum Schutz von der Umgebung und zur Unterstützung bei der Wärmeübertragung weg von der Batterie.

Zulieferer und OEMs benötigen gerade jetzt Unterstützung, wenn der Verkehrssektor sich weiter in Richtung Elektromobilität bewegt. Hier können wir mit unserem Materialwissen technische Hilfe anbieten. Durch eine Reihe von Kompatibilitätstests können die Experten von Dätwyler die richtige Lösung herausfinden und Dichtungen mit verschiedenen dielektrischen Flüssigkeiten kombinieren, wie beispielsweise mit Wasserglykolgemisch, Perfluorpolyether (PFPE), Kernöle - die eine umweltfreundlichere Alternative darstellen - und Silikonöle. In naher Zukunft steht wahrscheinlich das PFPE für die Elektromobilität besonders im Fokus, weil es eine niedrige Viskosität und nicht entflammbare Eigenschaften aufweist. Aber unabhängig davon, welche Flüssigkeit verwendet wird, ist es wichtig, dass Dichtungslösungen frühzeitig in der Entwicklungsphase beachtet werden. 